\title{
Synthesis and Reactivity of Zn-Biphenyl Metal-Organic Frameworks, Introducing a Diphenylphosphino Functional Group
}

\author{
Marco Ranocchiari ${ }^{\star a}$ and Jeroen Anton van Bokhoven ${ }^{\star a b}$
}

\begin{abstract}
Structural features, synthesis, and reactivity of Zn-biphenyl metal-organic frameworks with MOF-5 topology are presented to show the chemical flexibility of such materials and to demonstrate the challenges that can be encountered and solved to avoid interpenetration. We introduce the synthesis of a Zn-biphenyl MOF with diphenylphosphino functionalization and illustrate its structural and chemical properties.
\end{abstract}

Keywords: Metal-organic frameworks · MOF-5

\section{Introduction}

Metal-organic frameworks (MOFs) are coordination polymers (CPs) with a defined geometry and the ability to be porous. ${ }^{11]}$ They are made by multidentate organic linkers interconnected by inorganic units, which can be metals or metal clusters. Although their discovery dates back to the nineteen-fifties, they underwent exponential growth after work during the late nineties by Férey and Yaghi, ${ }^{[2]}$ who introduced MOFs that were highly porous and stable upon solvent removal. MOFs feature high porosity up to thousands of square meters per gram, which is ideal for gas/liquid storage and separation applications. ${ }^{[3]}$ Other applications, such as catalysis ${ }^{[4]}$ and medicinal chemistry ${ }^{[5]}$ can be found, although they are much less explored and at an early stage of development. As discussed in many reviews and perspectives, their porosity and the chemical and structural versatility is what makes them unique materials. ${ }^{[6]}$ On the one hand, the nature of the building blocks allows access to an almost infinite number of possible structural and chemical combinations. On the other hand, the rigid and ordered structure of the framework helps their growth as crystalline powders or single crystals to perform unique characterization.

The most studied MOFs are those that

"Correspondence: Dr. M. Ranocchiaria;

Prof. Dr. J. A. van Bokhoven ${ }^{\mathrm{ab}}$

Tel.: +414463255 42; +41563105046

E-mail: marco.ranocchiari@psi.ch;

jeroen.vanbokhoven@chem.ethz.ch

aLaboratory of Catalysis and Sustainable Chemistry

Paul Scherrer Institute

$\mathrm{CH}-5232$ Villigen $\mathrm{PSI}$

Laboratory for Chemical and Bioengineering

ETH Zurich

Wolfgang Pauli Strasse, 10

$\mathrm{CH}-8093$ Zürich can be properly characterized and that are sufficiently stable. A structure obtained from single crystal X-ray diffraction data is of great added value and provides a unique opportunity to monitor single-crystal-tosingle-crystal (SCSC) transformation and to elucidate the chemical behavior of the material. Solving and refining data from SC-XRD is far from trivial, though, and the high disorder of the systems usually hampers a precise determination of the structure. In this contribution, we will discuss the synthesis and structural features of Zn-biphenyl MOFs with MOF-5 topology ${ }^{[7]}$ to demonstrate the challenges that are encountered and that must be solved to properly characterize MOFs. We will analyze their structures and those of functionalized derivatives, whose reactivity will be presented. We will describe the advances towards the synthesis and characterization of a biphenyl Zn-MOF with ordered diphenylphosphino functionalization.

\section{IRMOF-9 and IRMOF-10}

MOFs with chelating carboxylate, sulfate, and phosphate organic linkers are the most studied because they generally give neutral frameworks with relatively high thermal stability. ${ }^{[6]}$ If they are threedimensional (3D) frameworks, they may also be stable upon removal of the guest molecules, which makes them extremely enticing for gas sorption/separation applications. [3] Most MOFs are still discovered serendipitously, but design is feasible and certainly easier when starting from a known topology and when rigid organic linkers and inorganic units are employed. One of the most cited MOF publications is on the highly porous MOF-5, which is made by terephthalate linkers connected by $\mathrm{Zn}_{4} \mathrm{O}$ clusters (Fig. 1a). ${ }^{[7]}$ Being one of the first relatively stable frameworks, the cubic topology of MOF-5 attracted a lot of attention towards research on new

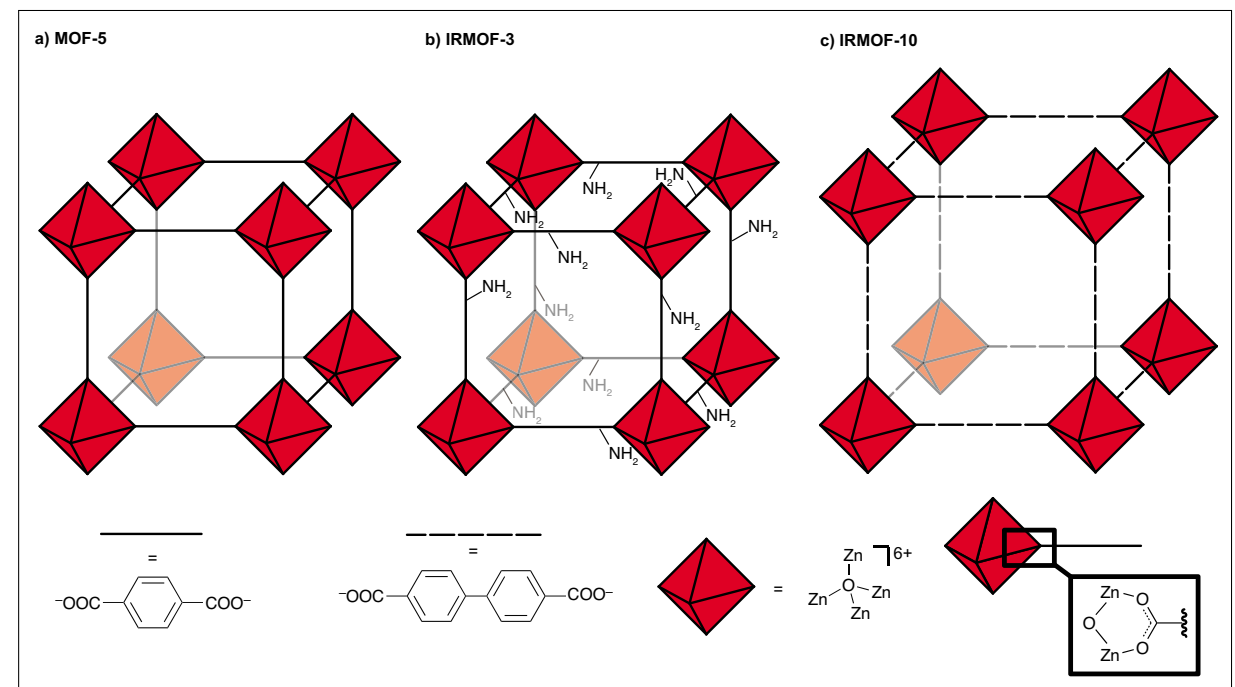

Fig 1. Schematic representation of IRMOF-3 (b) and IRMOF-10 (c) based on MOF-5 (a). 
MOF structures. The rigid nature of both the organic linker and the inorganic cluster allowed conceptualisation of isoreticular framework structures for the first time. ${ }^{[8]}$ The idea is to introduce different linkers with different functional groups and to tune the sorption properties of the materials by employing organic linkers with similar geometry to that of the starting MOF. For example, one can obtain an amino-functionalized MOF-5 by using aminoterephthalic acid in the solvothermal synthesis (Fig. 1b). One can increase the pore size by using longer organic linkers such as biphenyldicarboxylate (Fig. 1c).

The first and pioneering paper about isoreticularity presented two MOFs resulting from the biphenyldicarboxylate linker and MOF-5 topology, which were called IRMOF-9 and IRMOF-10 (Fig. 2). ${ }^{[8]}$ The first material was characterized by single-crystal XRD and featured two interpenetrated chains with MOF-5 topology, whereas the second was a non-interpenetrated IRMOF. It was not possible to grow single crystals of IRMOF-10 however, and the structure was derived from powder diffraction data. The first publication about biphenyl MOFs already anticipated the major challenges related to ZN-biphenyl MOFs: the growth of single-crystals and interpenetration.

The crystal structure of IRMOF-9 showed an orthorhombic unit cell with $a$ $=17.1469(8) \AA, b=23.3222(10) \AA, c=$ 25.2552(12) $\AA$, and space group Pnnm. The distance between the two interpenetrated networks $\left(\mathrm{d}_{\mathrm{F}-\mathrm{F}}\right)$ is $10.6 \AA$. A structure from single-crystal XRD of non-functionalized IRMOF-10 is not yet available.

\section{Functionalized IRMOF-9 and IRMOF-10: Structures and Post- Synthetic Modification Reactivity}

Some years after the IRMOFs publication of Yaghi and coworkers, ${ }^{[8]}$ an interest towards $\mathrm{Zn}$-biphenyl MOFs arose with the aim to introduce functionalization not participating in the framework structure that could undergo post-synthetic modification (PSM). ${ }^{[9]}$ The group of Burrows synthesized an aldehyde-tagged IRMOF-9 (IRMOF-9$\mathrm{CHO}$, Scheme 1), which was used for the condensation with dinitrophenylhydrazine to give the corresponding hydrazone by PSM. ${ }^{[10]}$ Data from single-crystal XRD showed that IRMOF-9-CHO adopted the doubly-interpenetrated cubic network observed previously for IRMOF-9. The high rotational disorder of the phenyl rings in the structure impeded the refinement of the aldehyde group in the ortho position. The structure of IRMOF-9-CHO is very similar to that of the non-functionalized analogue, but there are some differences. The

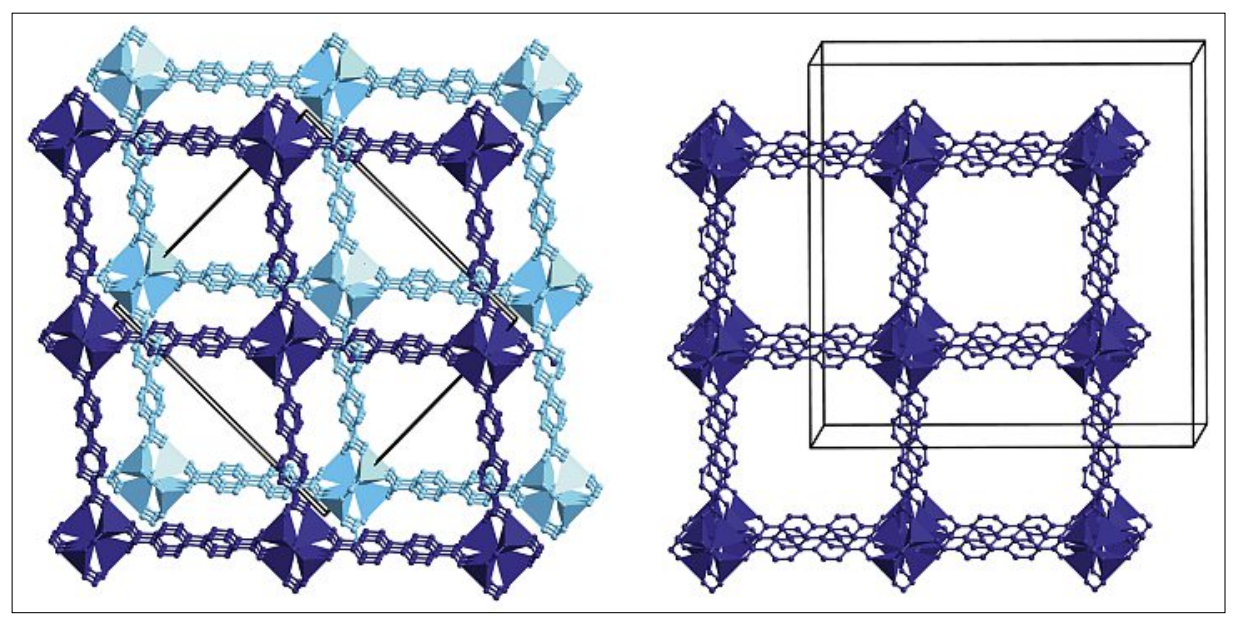

Fig. 2. Comparison of the schematic crystal structures of IRMOF-9 (left) and IRMOF-10 (right).

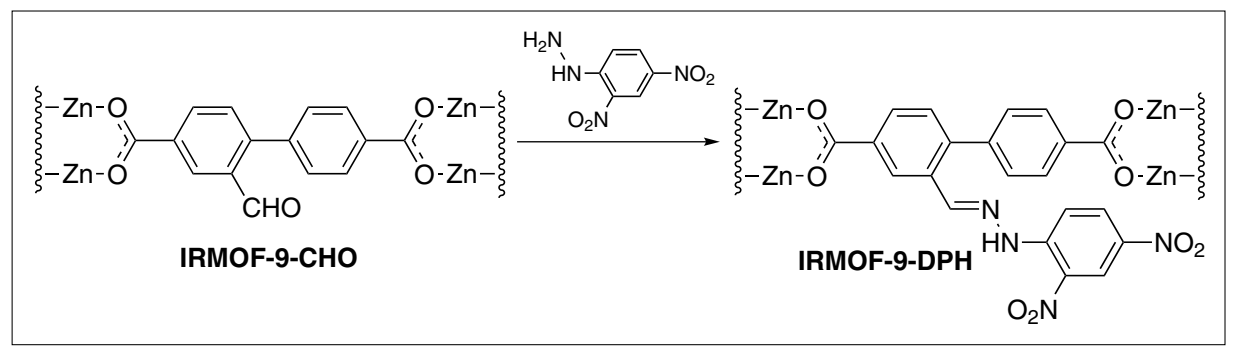

Scheme 1. PSM of IRMOF-9-CHO to give IRMOF-9-DPH.

aldehyde-functionalized MOF crystallizes in a monoclinic unit cell with dimensions $a=22.7990(19) \AA, b=25.218(3) \AA, c=$ 17.1200 (17) $\AA$ and $\beta=98.207(4)^{\circ}$. The distance between the two interpenetrated frameworks is $11.6 \AA$, which corresponds to an increase of about $1 \AA$ compared to the corresponding non-tagged MOF.

Functionalization of the aldehydetagged MOF with dinitrophenylhydrazine was performed in an SCSC fashion (Scheme 1). This allowed single-crystal XRD data of the hydrazone product IRMOF-9-DPH to be measured. The unit cell parameters substantially differed from those of the starting material (monoclinic with $a=24.3584(7) \AA, b=23.8485(7) \AA$, $\left.c=17.1987(5) \AA, \beta=93.465(2)^{\circ}\right)$ although the distance between the two interpenetrated frameworks remained comparable $\left(\mathrm{d}_{\mathrm{F}-\mathrm{F}}\right.$ $=11.5 \AA$ ). Interestingly, the phenyl rings show only little disorder, allowing the refinement of the atoms in the post-functionalized hydrazone tags to a certain extent. The torsion angle between the phenyl rings were on average lower than those observed in IRMOF-9-CHO indicating a distortion of the framework upon PSM reaction.

One year later, the same group published a series of sulfide-tagged MOFs isoreticular to IRMOF-9, which were post-synthetically oxidized to the sulfoxide with dimethyldioxirane (Fig. 3). ${ }^{[11]}$ Single-crystal diffraction data were obtained for IRMOF9- $\left(\mathrm{CH}_{2} \mathrm{SCH}_{3}\right)$, IRMOF-9- $\left(\mathrm{CH}_{2} \mathrm{SO}_{2} \mathrm{CH}_{3}\right)$, and IRMOF-9- $\left(\mathrm{CH}_{2} \mathrm{SCH}_{3}\right)_{2}$. The unit cell of IRMOF-9-( $\left.\mathrm{CH}_{2} \mathrm{SCH}_{3}\right)$ was monoclinic with cell parameters $a=25.0111(9) \AA$, $b=22.9843(9) \AA, c=17.2959(3) \AA, \beta=$ $96.404(4)^{\circ}$ and space group $C 2 / m$. The distance between the two frameworks was $11.6 \AA$ as found in IRMOF-9-CHO. Upon oxidation in an SCSC fashion, IRMOF-9- $\left(\mathrm{CH}_{2} \mathrm{SO}_{2} \mathrm{CH}_{3}\right.$ ) (monoclinic with $a=25.1670(4) \AA, b=23.2000(3) \AA$, $\left.c=17.1020(3) \AA, \beta=93.561(1)^{\circ}\right)$ was obtained. The structure is very similar to that of the starting material and the distance between the frameworks is also comparable.

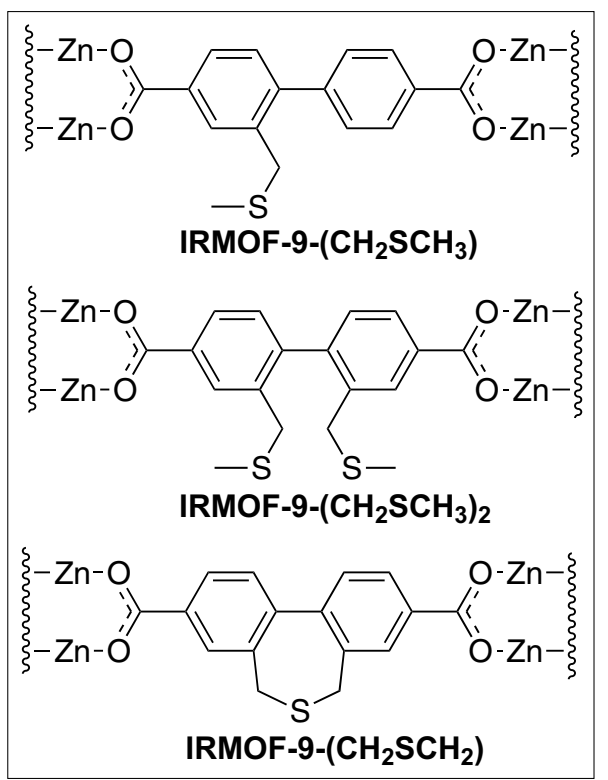

Fig. 3. Schematic representation of the organic building blocks of IRMOF-9- $\left(\mathrm{CH}_{2} \mathrm{SCH}_{3}\right)$, IRMOF-9- $\left(\mathrm{CH}_{2} \mathrm{SCH}_{3}\right)_{2}$, and IRMOF-9$\left(\mathrm{CH}_{2} \mathrm{SCH}_{2}\right)$. 
IRMOF-9- $\left(\mathrm{CH}_{2} \mathrm{SCH}_{3}\right)_{2}$ was different from all previous isoreticular IRMOF-9 structures. It crystallizes in the trigonal space group $R-3 m$ with the cell parameters $a=$ 23.8212(3) $\AA$ and $c=30.3938(1) \AA$. The two interpenetrated networks are only 8.6 $\AA$ apart, much closer than in any other interpenetrated MOF observed so far.

All Zn-biphenyl MOFs reported before 2010 were interpenetrated and therefore isostructural to IRMOF-9. A single-crystal $\mathrm{X}$-ray structure analysis of a non-interpenetrated IRMOF-10 derivative was not reported until the breakthrough of the group of Telfer, which showed how interpenetration can be effectively suppressed by using thermolabile protecting groups in the synthesis of amino-MOFs. ${ }^{[12]}$ Interestingly, when using the linker aminobiphenyldicarboxylic acid in the MOF synthesis, no amino MOF could be produced. If a $\mathrm{N}$-Boc protected linker was employed, a non-interpenetrated framework isostructural to IRMOF-10 with cubic unit cell was obtained ( $a=17.1728$ (3) $\AA$, space group $P-43 m)$. IRMOF-10-NHBoc was converted to the corresponding IRMOF-10- $\mathrm{NH}_{2}$ in a SCSC fashion by treatment at above $150{ }^{\circ} \mathrm{C}$ in DMF (Scheme 2). The cubic unit cell of IRMOF-10-NH resembled that of the reactant with $a=17.2184(6) \AA$ and space group $P-43 m$.

A similar strategy allowed the same group to introduce enantiomerically pure functionalization by using a N-Boc protected proline to yield the non-interpenetrated IRMOF-10 structures (Scheme $3) .{ }^{13]}$ The Boc group in IRMOF-10-ProBoc was cleaved in a SCSC transformation by treatment at $165^{\circ} \mathrm{C}$ in DMF to give IRMOF-10-Pro. Again single-crystal XRD revealed for both structures cubic unit cells with $P-43 m$ space group in analogy to the previous one.

Telfer's group published an analogous synthesis of a non-interpenetrated IRMOF-10 structure with phenol tags by exploiting a photolabile protecting group. ${ }^{[14]}$ If no protecting group was used and the phenol or methoxy ligands were employed as organic building blocks for the synthesis of the Zn-MOFs, the interpenetrated IRMOF-9 structure was observed. Single crystals were obtained for the IRMOF-9OMe structure, which featured a tetragonal unit cell with $a=17.2215(4) \AA, c=$ $17.1168(12) \AA$, space group $P-42_{1} m$, and $\mathrm{d}_{\mathrm{F}-\mathrm{F}}$ of $12.8 \AA$. On the other hand, the phenol-protected organic linker yielded the non-interpenetrated IRMOF-10-NBz structure, with the usual cubic cell, $a=$ $17.2108(17)$, and space group $P-43 m$. The phenol tags were revealed by treatment with $355 \mathrm{~nm}$ laser light while stirring in DMF to give IRMOF-10-OH (Scheme 4). Again the non-interpenetrated cubic structure was maintained.

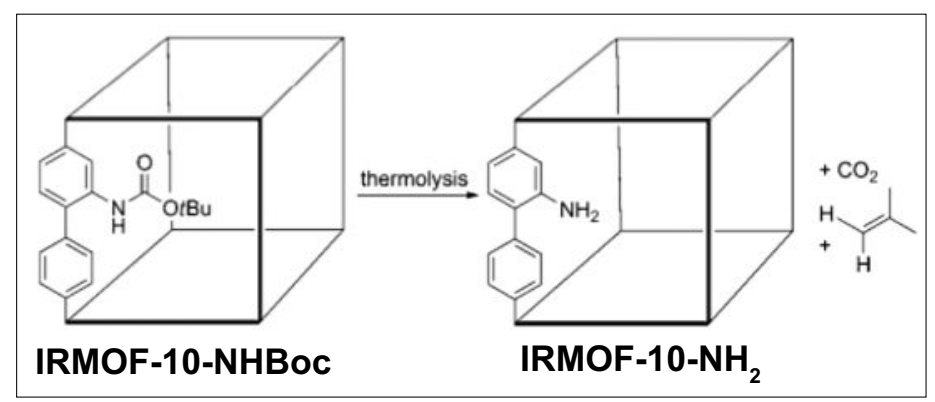

Scheme 2. Synthesis of IRMOF-10- $\mathrm{NH}_{2}$ from IRMOF-10NHBoc. Adapted with permission from ref. [12]. Copyright 2010 Wiley.

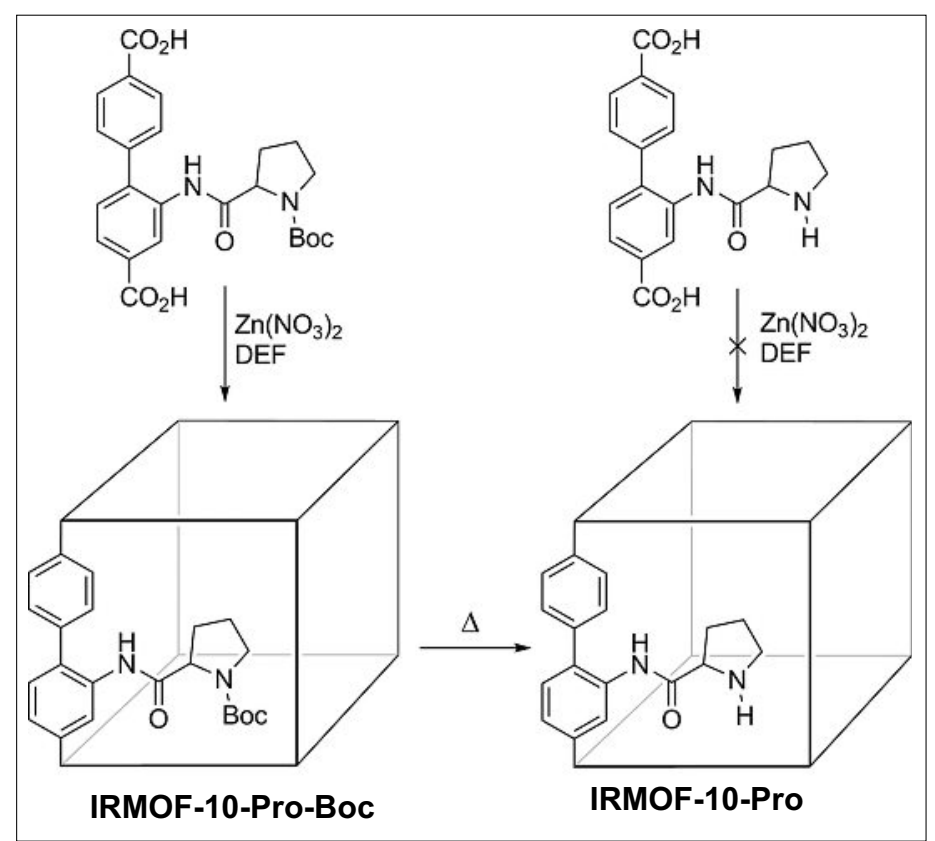

Scheme 3. Synthesis of IRMOF-10-Pro from the Bocprotected IRMOF10-Pro-Boc. Adapted with permission from ref. [13]. Copyright 2011 American Chemical Society.

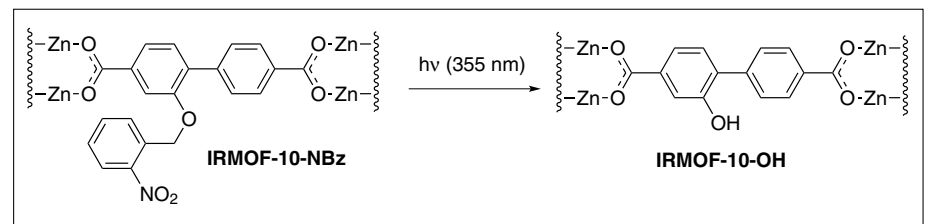

Scheme 4. Synthesis of IRMOF-10-OH from photolabile groups.

By looking at the structures above one can conclude that interpenetration is a major challenge that can be avoided, but it is hard to predict how and when. Telfer suggested that steric hindering groups such as the Boc and NBz groups hamper catenation. In a non-interpenetrated structure the torsion angle between the biphenyl rings is observed to be exactly $90^{\circ}$, which is not the case in almost all IRMOF-9 structures. However such a condition is not sufficient as seen in IRMOF-9-OMe, which features $90^{\circ}$ torsion angles and is interpenetrated. Steric hindering groups have therefore a twofold aim: i) to force the torsion angle of the phenyls to $90^{\circ}$ and ii) to occupy space to hamper aggregation of the second network inside the framework.

\section{LSK-3: IRMOF-9 with Diphenylphosphino Groups}

Our group synthesized a rationally designed, crystalline, and porous
P-functionalized MOF, which we call LSK-3, featuring IRMOF-9 topology and Lewis-basic sites that perform phosphine organocatalysis. ${ }^{[15]}$ The synthesis of the MOF was performed with mixed linkers from phosphine 1, [1,1'-biphenyl]-4,4'dicarboxylic acid (2), and $\mathrm{Zn}\left(\mathrm{NO}_{3}\right)_{2} \cdot 4 \mathrm{H}_{2} \mathrm{O}$ in dimethylformamide (DMF) under solvothermal conditions (Scheme 5a). Single-crystal X-ray crystallography revealed that such crystals featured a doubly interpenetrated cubic framework (Scheme 5c) with $\mathrm{Zn}_{4} \mathrm{O}$ inorganic units linked by biphenyl linkers (with or without P-functionalization), consistent with a framework with IRMOF-9 topology. LSK3 crystallizes in the tetragonal space group $P 4_{2} / \mathrm{ncm}$ with the lattice parameters $a=$ 17.2209(11) $\AA$ and $c=34.229(2) \AA$. The distance between the two interpenetrated networks $\left(\mathrm{d}_{\mathrm{F}-\mathrm{F}}\right)$ was $12.9 \AA$, which is the largest among IRMOF-9 derivatives. A large $\mathrm{d}_{\mathrm{F}-\mathrm{F}}$ is needed to accommodate the diphenylphosphino groups. ICP analysis of the material gave a $\mathrm{P}: \mathrm{Zn}$ ratio of 0.24 , and 
${ }^{1} \mathrm{H}$ NMR spectroscopy, after digestion of a single crystal of LSK-3 in DCl $/ d^{6}$-DMSO, revealed that the ratio of the two linkers 1 and 2 in the MOF to be 0.5. This combined information confirmed the expected $\left[\mathrm{Zn}_{4} \mathrm{O}(\mathbf{2})_{2}(\mathbf{1})\right]$ stoichiometry of LSK-3, in agreement with single crystal X-ray data and with previously reported IRMOF-9 and IRMOF-10 structures.

Interestingly, the diphenylphosphinegroups are located exclusively on the linkers oriented in the $a-b$ plane (Scheme $5 b$ and Fig. 4). This is a unique example of a MOF in which mixed linkers of the same type and size are in preferential directions of the unit cell. Such structural uniqueness of LSK-3 might open perspectives in the synthesis of new ordered multifunctionalized MOFs for application in multi-functional catalysis. The screening of the ratio between the two linkers in the solvothermal synthesis of LSK-3 showed that a $1: 2$ ratio lower than 0.5 (down to 0.2 ) yielded a solid crystalline phase with powder XRD pattern comparable to that calculated from the single crystal XRD (see below). A phase isostructural to IRMOF-9 with diphenylphosphino groups randomly and homogeneously distributed within the framework, was produced by using a 1:2 ratio lower than 0.2 , as detected by single crystal X-ray diffraction and ${ }^{31} \mathrm{P}$ MAS NMR spectroscopy.[16]

An in-depth analysis of the Connolly surface of LSK-3 ${ }^{[17]}$ revealed that, if diphenylphosphino moieties are not taken into account, two-dimensional (2D) channels with rectangular and perpendicular pore openings of $6.1 \AA \times 8.4 \AA$ (channel 2 in Fig. 5) and $6.9 \AA \times 8.4 \AA$ (channel 1 in Fig. 5) are present. Such channels are constituted by cavities that might contain up to two diphenylphosphino moieties (depicted in blue in Fig. 5), which are interconnected by two types of cavities of $5.9 \AA \times 6.1 \AA$ $\times 8.4 \AA$ and $6.7 \AA \times 6.9 \AA \times 8.4 \AA$ that do not contain phosphorus (depicted in yellow in Fig. 5). In the presence of diphenylphosphino groups, the blue cavities reduce their open space, and four different pores, whose shape depends on the number and location in space of the phosphine sites, can be distinguished. Cavities of type A with no diphenylphosphino groups can be fitted with a parallelepiped of $6.1 \AA \times 6.9$ $\AA \times 8.4 \AA$ with volume $350 \AA^{3}$. One diphenylphosphino group decreases the volume of the cavity to $270 \AA^{3}$. Although only one position of the diphenylphosphino moiety is shown in Fig. 5, three alternative orientations (upper-right-front, lower-left-back, upper-right-back) are possible as evident by the crystal structure and by the symmetry of the system. Two diphenylphosphino groups in the same cage can be adjacent and form cavities of type $\mathrm{C}$ with volume of $208 \AA^{3}$ or can be on opposite sides and

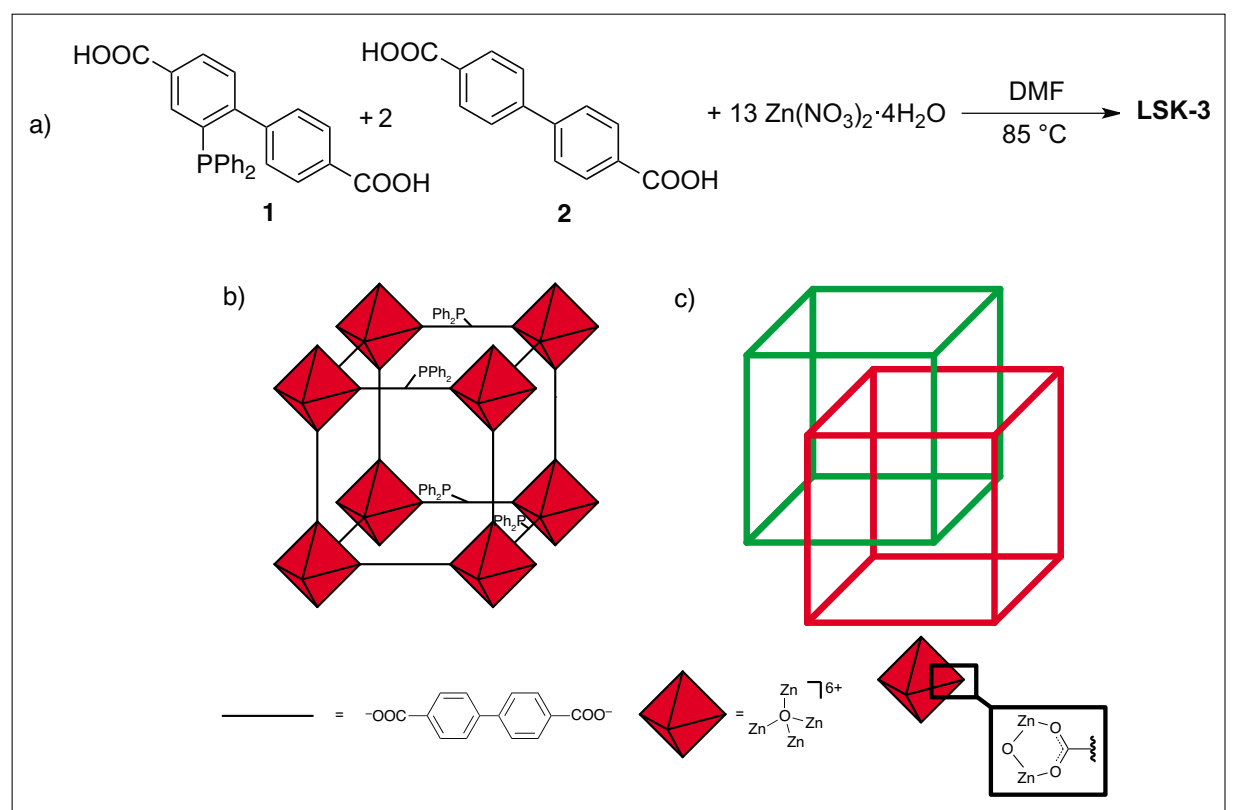

Scheme 5. a) Synthesis of LSK-3. b) Schematic representation of LSK-3. Only one of the two interpenetrated frameworks is shown for clarity. For a crystal structure from X-ray diffraction data see Fig. 4. c) Schematic structure of the two interpenetrated frameworks, one cube represents the same structure as in b).

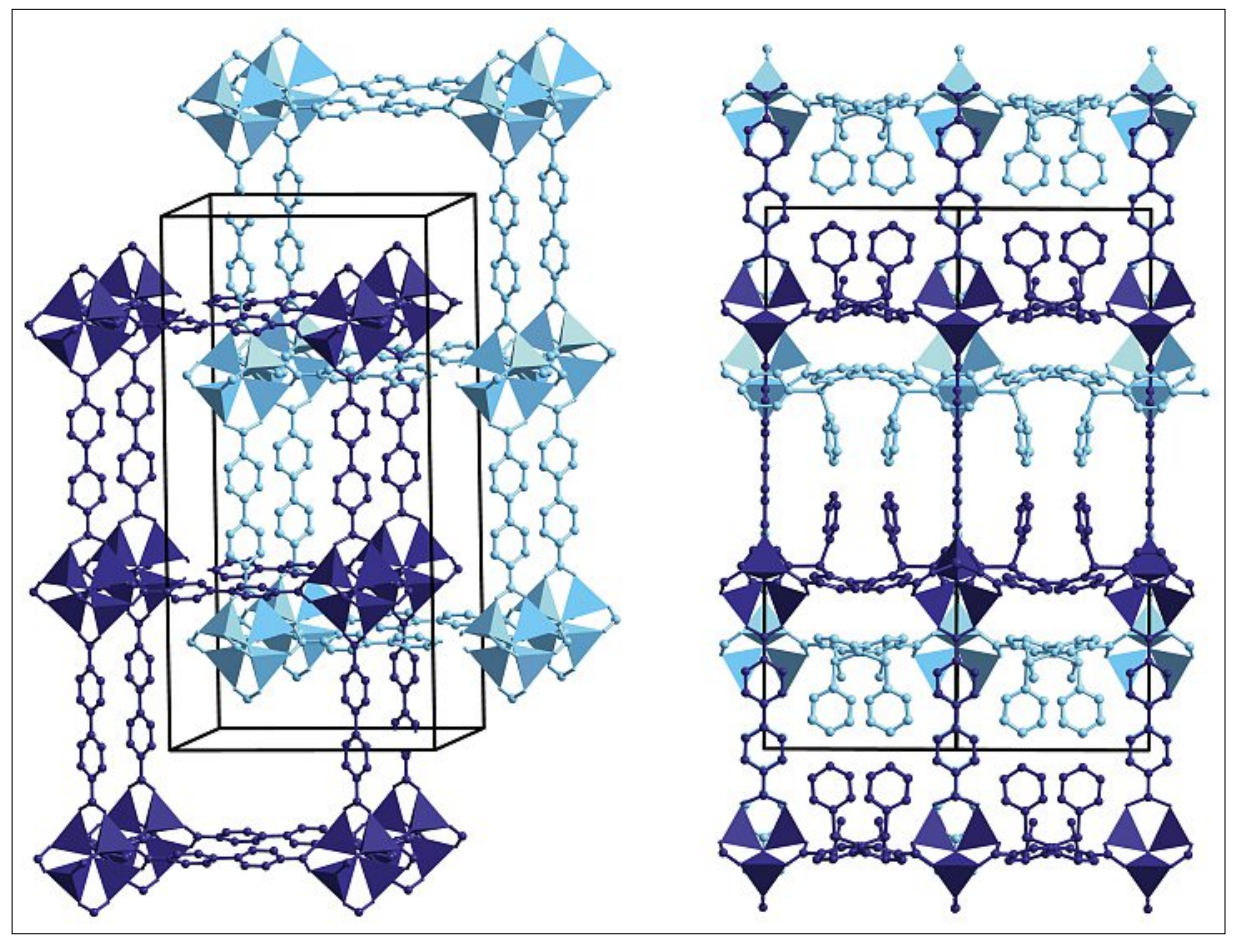

Fig. 4. A view of the interpenetrated framework of LSK-3 (left, diphenyl-groups, solvent and split atom positions are omitted for clarity) and a view along the [110]-direction (right) showing a possible arrangement of the disordered diphenyl-phosphine group within the channels of the crystal structure.

produce cavities of type $\mathrm{D}$ with volume of $192 \AA^{3}$. Once again, only one of the two possible orientations is shown in the figure for clarity. Nitrogen physisorption measurements at $77 \mathrm{~K}$ of the MOF activated with supercritical $\mathrm{CO}_{2}^{[18]}$ showed a type- 1 isotherm with BET surface area of $900 \mathrm{~m}^{2} / \mathrm{g}$ and $\mathrm{t}$-plot pore volume of 0.25 $\mathrm{cm}^{3} / \mathrm{g}$, in agreement with Connolly surface calculations.

\section{Conclusions}

Zn-biphenyl MOFs with MOF-5 topology are materials with big pores that are relatively easy to synthesize. Their synthesis presents major challenges to avoid interpenetration, which can be controlled by introducing bulky protecting groups that force the biphenyl torsion angle to $90^{\circ}$ and avoid aggregation of a second interwoven chain during synthesis. IRMOF-9 


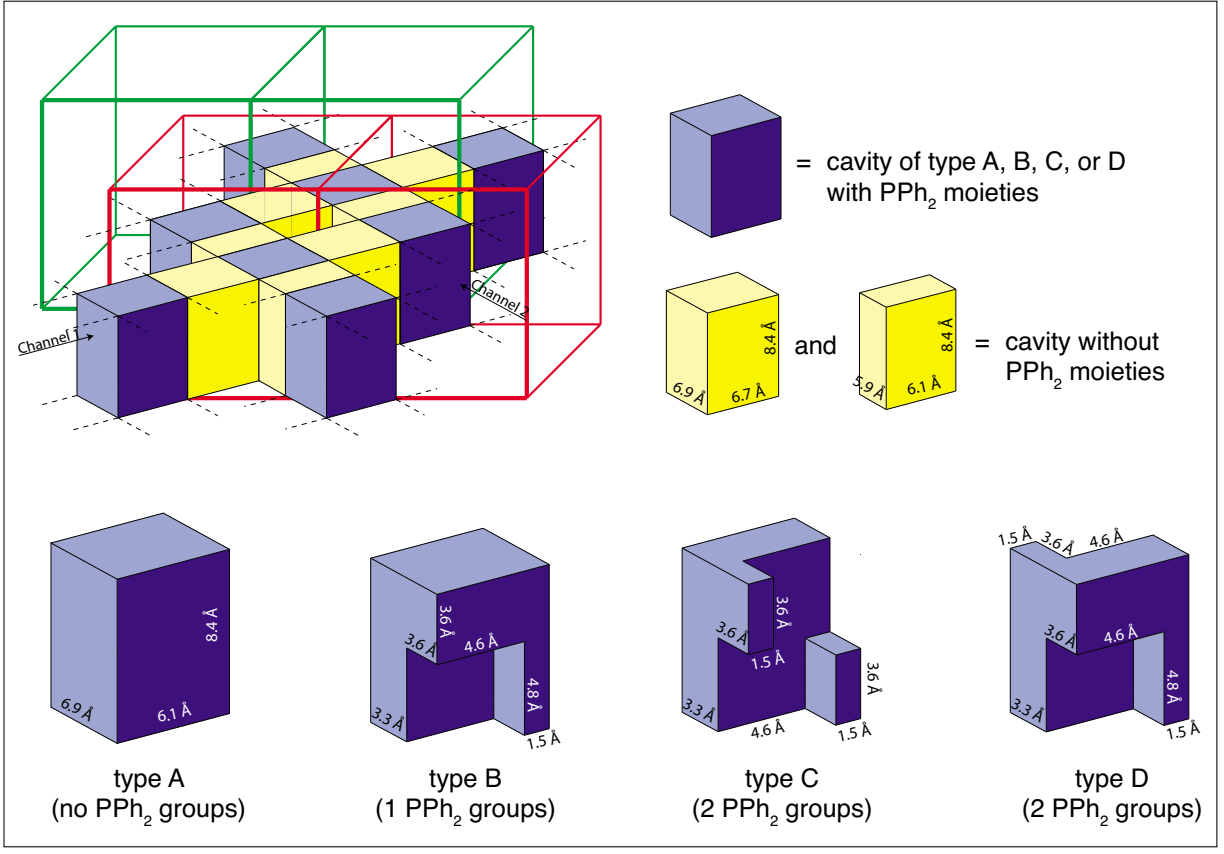

Fig. 5. Schematic representation of the pore structure of LSK-3. The green and red cubes represent the two interpenetrated networks of the material.

and IRMOF-10 and their isoreticular derivatives are promising materials useful for application in separation technology and catalysis. Materials with free phosphine moieties such as LSK-3 will open new perspectives in catalysis due to their Lewis basicity and possibility to coordinate transition metals together with their open channel structure.

\section{Experimental Part}

\section{Synthesis of LSK-3}

[1,1'-Biphenyl]-4,4'-dicarboxylic acid $(2,0.059 \mathrm{~g}, 0.24 \mathrm{mmol})$ and $1(0.052 \mathrm{~g}$, $0.12 \mathrm{mmol})^{[19]}$ were placed into a $20 \mathrm{~mL}$ scintillation vial. The vial was flushed with $\mathrm{Ar}$ and a solution of $\mathrm{Zn}\left(\mathrm{NO}_{3}\right)_{2}(0.286 \mathrm{~g}$, $1.51 \mathrm{mmol}$ ) in $15 \mathrm{~mL}$ degassed DMF was added. The vial was tightly closed and the suspension was heated in an oven at $85{ }^{\circ} \mathrm{C}$ for $72 \mathrm{~h}$. Single crystals of $0.5-2.0 \mathrm{~mm}$ size were measured directly after synthesis. For long term storage and application in catalysis, the solvent was decanted, the crystals were washed with $3 \times 5 \mathrm{~mL}$ degassed DMF and $5 \mathrm{~mL}$ degassed chloroform was added. Chloroform was exchanged 3 times over three days and the crystals were stored in degassed toluene. ${ }^{1} \mathrm{H}$ NMR spectroscopy of the material digested in $\mathrm{DCl} / d^{6}$-DMSO showed a ratio $1: 2$ of 0.5 . BET surface area $=900 \mathrm{~m}^{2} / \mathrm{g}$. t-plot pore volume $=0.25$ $\mathrm{cm}^{3} / \mathrm{g}$. ${ }^{31}$ PMAS-NMR (162 MHz) $\delta(\mathrm{ppm})$ : $-14.8(\mathrm{~s})$

\section{X-ray Crystal Structure Analysis of LSK-3}

Single crystals of LSK-3 $\left(\mathrm{C}_{54} \mathrm{H}_{33} \mathrm{O}_{13} \mathrm{Zn}_{4} \mathrm{P}\right)$ were selected under a mi- croscope using polarized light. Since the crystals decompose very quickly on loss of solvent, they were examined while still covered by mother liquor. A suitable crystal was selected and mounted on the tip of a Mark-tube using perfluorinated polyether oil, quickly transferred into the cold nitrogen beam and shock frozen to $230 \mathrm{~K}$. The data collection was performed on a Bruker SMART Platform diffractometer equipped with a CCD-Detector.

Temperature-dependent diffraction experiments show that below $195 \mathrm{~K}$ a reversible phase transition occurs, characterized by the smearing of high angle reflections along the crystallographic $c$-axis and a strong decrease of the maximum diffraction angle $\left(\mathrm{d}_{\text {min }}\right.$ rises from about $1 \AA$ to only about $1.3 \AA$ ) ). Therefore the crystal was kept at $230 \mathrm{~K}$ during data collection. The diffraction pattern shows besides sharp reflections up to a maximum of about $2 \theta=$ $45^{\circ}$, areas with strong diffuse intensities, indicating disorder in the crystal structure. It is a frequent observation that the quality of the diffraction patterns of MOFs decreases while cooling (see for example ref. [14]). The melting point of DMF is with $212 \mathrm{~K}$ close to the observed transition at $195 \mathrm{~K}$. Accordingly a possible reason for this behavior might be the freezing of the disordered DMF in the cavities. This may lead to distortions of the frameworks and therefore to an increased disorder.

The analysis of the systematic absences leads to the space group $P 4_{2} / \mathrm{ncm}$. Using Olex2,[20] the structure was solved with the $\mathrm{XS}^{[21]}$ structure solution program using Direct Methods and refined with the XL[22] refinement package using Least Squares minimization.
As already indicated by the occurrence of diffuse intensities in the diffraction pattern, the crystal structure turns out to be heavily disordered. The disorder was described as split positions whenever possible. Therefore, isotropic displacement parameters were applied for all $\mathrm{C}$ and most $\mathrm{O}$ atoms. The $\mathrm{Zn}-$, $\mathrm{P}$ - and some O-atom positions were described by anisotropic displacement parameters. $\mathrm{H}$-atoms were placed at calculated positions and included in the refinement using the riding model. The occupancy factor of the $\mathrm{P}(\mathrm{Ph})_{2}$-substituent was fixed to $1 / 4$, according to the ratio of spacer-molecules in the material. The resulting displacement parameters were reasonable for this occupancy. Solvent molecules are heavily disordered and were described as partially occupied C-atoms. In total about $57 \mathrm{C}$-atom equivalents were found in the unit cell, corresponding to about $8 \mathrm{DMF}-$ molecules per unit cell and 2 per formula unit. In the voids of the structure weak residual electron density originating from disordered solvent molecules remains. The refinement converges to an R1-value (based on F) of $12.7 \%$. In the voids of the structure many weak residual electron density peaks originating from disordered solvent molecules could be detected. To account for this effect the program SQUEEZE[23] was employed. The refinement converges then at a final R1-value of $10.2 \%$.

\section{Crystal Data}

The crystal composition refined was $\mathrm{C}_{683025} \mathrm{H}_{33} \mathrm{O}_{13} \mathrm{Zn}_{4} \mathrm{P}$, which corresponds to a framework consisting of $\mathrm{Zn}_{4} \mathrm{O}$, two unsubstituted biphenyl-linkers and one $\mathrm{Ph}_{2} \mathrm{P}$ substituted linker and about 2.15 DMF molecules in the cavities. $M=1354.03$, tetragonal, $a=17.2209(11) \AA, c=34.229(2) \AA$, $V=10150.8(11) \AA^{3}, T=230.15$, space $\operatorname{group} P 4_{2} / n c m($ no. 138), $Z=4, \mu($ MoK $\alpha)=$ $0.988,66340$ reflections measured, 3852 unique $\left(R_{\text {int }}=0.0668\right)$ which were used in all calculations. The final $w R$, was 0.3524 (all data) and $R_{1}$ was 0.1269 (>2sigma(I)). The $R_{1}$ was 0.1021 ( $\left.>2 \operatorname{sigma}(\mathrm{I})\right)$ if the SQUEEZE program was applied. ${ }^{[23]}$ CCDC 928710 contains the supplementary crystallographic data for this paper. These data can be obtained free of charge from The Cambridge Crystallographic Data Centre via www.ccdc.cam.ac.uk/data_request/cif.

\section{Acknowledgement}

We thank Dr. Michael Wörle for the helpful discussions and single-crystal X-ray investigation on LSK-3.

Received: March 31, 2013

[1] S. R. Batten, N. R. Champness, X.-M. Chen, J. Garcia-Martinez, S. Kitagawa, L. Öhrström, M. O'Keeffe, M. P. Suh, J. Reedijk, CrystEngComm 2012, 14, 3001. 
[2] a) H. Li, M. Eddaoudi, T. L. Groy, O. M. Yaghi, J. Am. Chem. Soc. 1998, 120, 8571; b) D. Riou, O. Roubeau, G. Férey, Microporous Mesoporous Mater. 1998, 23, 23.

[3] a) J.-R. Li, R. J. Kuppler, H.-C. Zhou, Chem. Soc. Rev. 2009, 38, 1477; b) R. J. Kuppler, D. J. Timmons, Q.-R. Fang, J.-R. Li, T. A. Makal, M. D. Young, D. Yuan, D. Zhao, W. Zhuang, H.-C. Zhou, Coord. Chem. Rev. 2009, 253, 3042.

[4] a) J. Lee, O. K. Farha, J. Roberts, K. A. Scheidt, S. T. Nguyen, J. T. Hupp, Chem. Soc. Rev. 2009, 38, 1450; b) A. Corma, H. García, F. X. Llabrés i Xamena, H. Garcia, F. X. i Xamena, Chem. Rev. 2010, 110, 4606; 1. c) M. Ranocchiari, J. A. van Bokhoven, Phys. Chem. Chem. Phys. 2011, 13, 6388 .

[5] P. Horcajada, R. Gref, T. Baati, P. K. Allan, G. Maurin, P. Couvreur, G. Férey, R. E. Morris, C. Serre, Chem. Rev. 2012, 112, 1232.

[6] a) S. Kitagawa, R. Kitaura, S. Noro, Angew. Chem. Int. Ed. 2004, 43, 2334; b) G. Férey, Chem. Soc. Rev. 2008, 37, 191.
[7] H. Li, M. Eddaoudi, M. O’Keeffe, O. M. Yaghi, Nature 1999, 402, 276

[8] M. Eddaoudi, J. Kim, N. Rosi, D. Vodak, J. Wachter, M. O'Keeffe, O. M. Yaghi, Science 2002, 295, 469.

[9] S. M. Cohen, Chem. Rev. 2012, 112, 970.

[10] A. D. Burrows, C. G. Frost, M. F. Mahon, C. Richardson, Angew. Chem. 2008, 120, 8610.

[11] A. D. Burrows, C. G. Frost, M. F. Mahon, C. Richardson, Chem. Commun. 2009, 4218.

[12] R. K. Deshpande, J. L. Minnaar, S. G. Telfer, Angew. Chem. Int. Ed. 2010, 49, 4598.

[13] D. J. Lun, G. I. N. Waterhouse, S. G. Telfer, J. Am. Chem. Soc. 2011, 133, 5806.

[14] R. K. Deshpande, G. I. N. Waterhouse, G. B. Jameson, S. G. Telfer, Chem. Commun. 2011, 48,3 .

[15] X. Xu, S. M. Rummelt, F. L. Morel, M. Wörle, M. Ranocchiari, J. A. van Bokhoven, unpublished results.

[16] a) H. Deng, C. J. Doonan, H. Furukawa, R. B. Ferreira, J. Towne, C. B. Knobler, B. Wang,
O. M. Yaghi, Science 2010, 327, 846; b) M. C. Das, S. Xiang, Z. Zhang, B. Chen, Angew. Chem. Int. Ed. 2011, 50, 10510; c) T. Lescouet, E. Kockrick, G. Bergeret, M. Pera-Titus, S. Aguado, D. Farrusseng, J. Mater. Chem. 2012, 22, 10287.

[17] M. L. Connolly, J. Appl. Crystallogr. 1983, 16, 548. The Connolly surface was calculated with Accelrys Materials Studio 6.0.

[18] A. P. Nelson, O. K. Farha, K. L. Mulfort, J. T. Hupp, J. Am. Chem. Soc. 2009, 131, 458.

[19] S. M. Rummelt, M. Ranocchiari, J. A. van Bokhoven, Org. Lett. 2012, 14, 2188.

[20] O. V. Dolomanov, L. J. Bourhis, R. J. Gildea, J. A. K. Howard, H. Puschmann, J. Appl. Crystallogr. 2009, 42, 339.

[21] SHELXS-97, G. M. Sheldrick, 2008.

[22] G. M. Sheldrick, Acta Cryst. A 2008, 64, 112.

[23] A. L. Spek, Acta Cryst. D 2009, 65, 148. 